\title{
The Experimental Study on BFRP Rebar and Coral Concrete Bond
}

\section{Performance}

\author{
Jiayi $\mathrm{Li}^{1, \mathrm{a}}$ \\ ${ }^{1}$ School of Civil Engineering, Guilin University of Technology, Guilin 51004, China; \\ a945290186@qq.com
}

Keywords: Coral concrete, BFRP rebar, pull-out test, bond performance

\begin{abstract}
With the pull-out test on 30 specimens, influences on bond performance between them were studied by changing diameter of BFRP rebar, coral concrete compression strength and bond length of BFRP rebar in coral concrete, respectively. The study indicates that the limit bond strength between BFRP rebar and coral concrete will be reduced with the increase of BFRP rebar's diameter and its bond length in coral concrete. To some extent, the increase of compression strength for coral concrete will improve bond strength.
\end{abstract}

\section{Introduction}

In recent years, with the development and construction of South China Sea, coral concrete of which aggregate is coral detritus has been greatly concerned by an increasing number of people. Coral concrete contains more chloridion, which may speed up corrosion of rebar, resulting in unsuitable utilization between them and affecting application and promotion of coral concrete components directly ${ }^{[1]}$. Based on it, Fiber Reinforcement Polymer rebar (FRP rebar) is used to replace rebar in coral concrete to solve corrosion of rebar effectively. In order to normally use FRP rebar and coral concrete, it must ensure good bond performance between them. Unfortunately, domestic and overseas studies on their bond performance are almost blank, so it is necessary to study bond performance between FRP rebar and coral concrete, so as to widely apply coral concrete and realize the imagination of making coral concrete elements. In the paper, BFRP rebar, which is one of the categories in FRP rebar, to study influences on their bond performance by changing diameter of BFRP rebar, coral concrete compression strength and bond length of BFRP rebar in coral concrete, respectively.

\section{Test Design}

The pull-out test was applied. Specimens were stipulated according to Test Method Standard for Concrete Structure (GB-50152-92). A total of 30 put-out specimens in 10 groups were poured in $150 \mathrm{~mm} \times 150 \mathrm{~mm} \times 150 \mathrm{~mm}$. In order to avoid from a large difference between stress state and actual structure around the end of fiber rebar, which may be suffered from local extrusion in loading end concrete of specimens, the plastic sleeve was used to separate from concrete and fiber rebar within certain length of loading end ${ }^{[2]}$, the simulative bond length can be realized by adjusting plastic sleeve.

With ribbed thread on the surface of BFRP rebar, the surface treatment was concave tooth. 
Coral concrete is composed of coral detritus, middle-coarse river sand, ordinary Portland cement and artificial sea water (which is configured as water: sea salt $=100: 3$ ). Source area of coral detritus is Weizhou Island in Beihai, Guangxi. With the shapes of strips and blocks, it is a natural lightweight aggregate with multiple holes. The design strength is C30, C20 and C15. By referring to Technical Regulations of Light-weight Aggregate Concrete (JGJ51-2002) and research results of other scholars, mix proportion of coral concrete required in the test is shown in Table $1^{[3]}$.

Table 1 Mix Proportion of Coral Concrete

\begin{tabular}{cccccc}
\hline $\begin{array}{c}\text { Concrete } \\
\text { grade }\end{array}$ & $\begin{array}{c}\text { Water-cement } \\
\text { ratio }\end{array}$ & $\begin{array}{c}\text { Cement } \\
\left(\mathrm{kg} / \mathrm{m}^{3}\right)\end{array}$ & $\begin{array}{c}\text { Coral } \\
\left(\mathrm{kg} / \mathrm{m}^{3}\right)\end{array}$ & $\begin{array}{c}\text { Medium sand } \\
\left(\mathrm{kg} / \mathrm{m}^{3}\right)\end{array}$ & $\begin{array}{c}\text { Seawater } \\
\left(\mathrm{kg} / \mathrm{m}^{3}\right)\end{array}$ \\
\hline C15 & 0.53 & 340 & 716 & 830 & 180 \\
C20 & 0.47 & 380 & 716 & 830 & 180 \\
C30 & 0.40 & 450 & 716 & 830 & 180 \\
\hline
\end{tabular}

3. Test Results and Analysis

The pull-out test was implemented on 30 specimens, as shown in Table 2 for relevant results Table 2 Pull-out Test Results

\begin{tabular}{ccccccc}
\hline No. & $\begin{array}{c}\text { Strength Grade of } \\
\text { Coral Concrete }\end{array}$ & $\begin{array}{c}\mathrm{d} \\
(\mathrm{mm})\end{array}$ & $\begin{array}{c}\mathrm{l}_{\mathrm{a}} \\
(\mathrm{mm})\end{array}$ & $\begin{array}{c}\mathrm{F}_{\max } \\
(\mathrm{kN})\end{array}$ & $\begin{array}{c}\mathrm{S}_{\max } \\
(\mathrm{mm})\end{array}$ & $\begin{array}{c}\tau_{\max } \\
(\mathrm{MPa})\end{array}$ \\
\hline 1 & $\mathrm{C} 30$ & 6 & $5 \mathrm{~d}$ & 8.60 & 1.88 & 15.21 \\
2 & $\mathrm{C} 30$ & 8 & $5 \mathrm{~d}$ & 15.10 & 1.66 & 15.03 \\
3 & $\mathrm{C} 30$ & 10 & $5 \mathrm{~d}$ & 22.73 & 1.46 & 14.48 \\
4 & $\mathrm{C} 30$ & 10 & $10 \mathrm{~d}$ & 41.25 & 1.40 & 13.14 \\
5 & $\mathrm{C} 30$ & 10 & $12 \mathrm{~d}$ & 47.75 & 0.78 & 12.67 \\
6 & $\mathrm{C} 30$ & 12 & $5 \mathrm{~d}$ & 32.10 & 2.84 & 14.20 \\
7 & $\mathrm{C} 30$ & 16 & $5 \mathrm{~d}$ & 53.95 & 1.63 & 13.42 \\
8 & $\mathrm{C} 30$ & 20 & $5 \mathrm{~d}$ & 66.05 & 2.39 & 10.52 \\
9 & $\mathrm{C} 20$ & 10 & $10 \mathrm{~d}$ & 31.80 & 1.73 & 10.13 \\
10 & $\mathrm{C} 15$ & 10 & $10 \mathrm{~d}$ & 26.25 & 1.46 & 8.36 \\
\hline
\end{tabular}

Notes: a. Symbols in the table are shown as follows: $d$ - diameter of BFRP rebar; bond length between BFRP rebar and coral concrete; $\mathrm{F}_{\max }$-Maximal load in test process; $\mathrm{S}_{\max }$ - Slippage as maximum load; $\tau_{\max }$ - bond stress as maximal load

b. In the above-mentioned data, the specimen that was closest to the mean of maximal load was chosen from three specimens. The result was used for the central value.

In the test, the formula $\tau_{u i}=\frac{F_{i}}{1}$ was applied to calculate mean bond stress $\tau_{\mathrm{ui}}$.

In the dial indicators, slippage $S_{1}^{\pi d} l_{a n d} S_{2}$ on loading end and free end of the corresponding BFRP rebar under load value $F_{i}$ were calculated for mean relative slippage $S_{i}$, which was used as $X$-axis. $\tau_{\mathrm{ui}}$ was the Y-axis for bond stress-slippage $\operatorname{curve}\left(\tau_{\mathrm{ui}}-\mathrm{S}_{\mathrm{i}}\right.$ curve $)$, so as to study the influence on bond performance between them by changing diameter of BFRP rebar, coral concrete compression strength and bond length of BFRP rebar in coral concrete.

\subsection{Influences of Diameter of BFRP Rebar on Bond Performance ${ }^{[4]}$}

When coral concrete compression strength and bond length of BFRP rebar in coral concrete are the same, the bond stress-slippage curves of BFRP rebar with the diameter of $6 \mathrm{~mm}, 8 \mathrm{~mm}, 10 \mathrm{~mm}$ and $12 \mathrm{~mm}$ are shown in Figure 1. It can be observed from the figure that as increasing diameter of BFRP 
rebar, the maximal bond stress will be reduced. Reasons are attributed as follows:1. The thicker BFRP rebar is, the larger sectional area will be and the larger perimeter will be. On the contrary, the specific value between the latter and the former will be smaller. Under the larger loads, it is not good for increasing the maximal bond stress. 2. The thicker BFRP rebar is, the worse pouring compaction will be. It can't better bind with coral concrete, resulting in reduction of maximal bond stress.

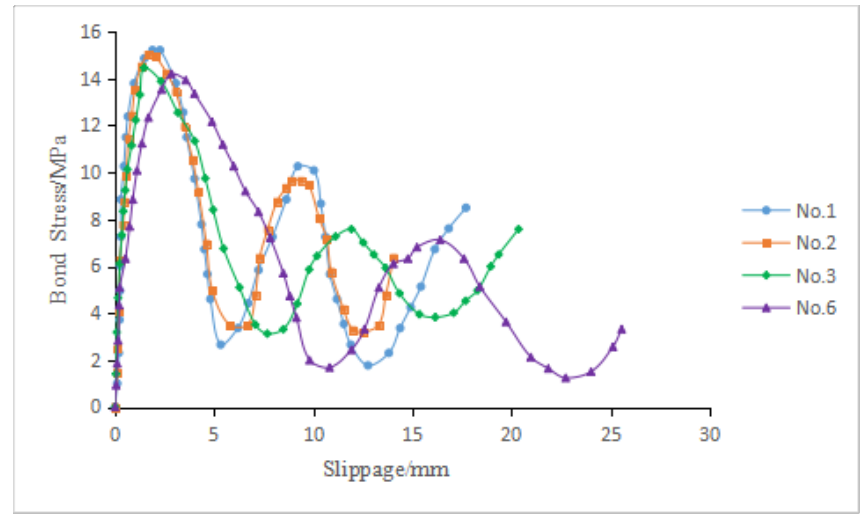

Fig. 1 Bond Stress - Slippage Curves of BFRP Rebar with Different Diameters and Coral Concrete

\subsection{Influences of Cube Crushing Strength of Coral Concrete on Bond Performance}

When diameter of BFRP rebar and bond length of BFRP rebar in coral concrete are the same, bond stress - slippage curves of specimens with the coral concrete compression strength of C30, C20 and $\mathrm{C} 15$ are shown in Figure 2. It can be observed from the figure that with the increase of coral concrete compression strength, the maximal bond stress also will be increased constantly, because it is related to the bonding power between them.

Italian Scholar E. Cosenza ${ }^{[5]}$ thinks that binding power between FRP rebar and concrete is similar to ordinary reinforced concrete and is composed of chemical cohesive action(namely chemical glue force) between FRP rebar and concrete, shrinkage of concrete caused by temperature changes or dry-wet cycle or wrapping action(namely wrapping friction) generated by FRP rebar's volume expansion, and occlusion action for slippage prevention generated by FRP rebar surface deformation(such as thread, groove and indentation, etc) and concrete. By applying the above-mentioned conclusion to BFRP rebar and coral concrete, it can be found that when the latter compression strength is higher, the chemical glue force generated by cement gel on BFRP rebar surface and mechanical bite force caused by rough BFRP rebar surface shape are larger. Meanwhile, tensile strength of coral concrete also will be increased, preventing from developing crack around the bottom specimens to BFRP rebar surface to improve maximal bond stress. 


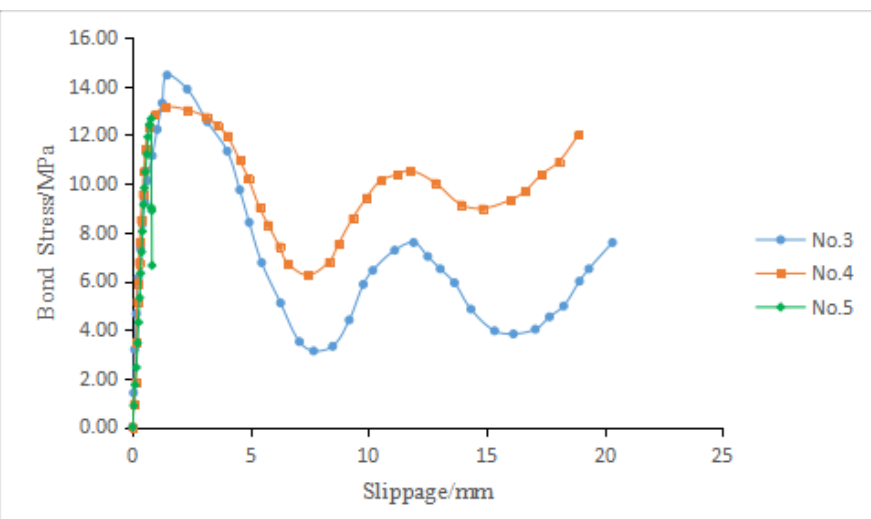

Fig. 2 Bond Stress - Slippage Curves of Coral Concrete with Different Compression Strength and BFRP Rebar

\subsection{Influences of BFRP Rebar's Bond Length in Coral Concrete on Bond Performance}

When diameter of BFRP rebar and coral concrete compression strength are the same, bond stress - slippage curves of specimens with the BFRP rebar's bond length of 5d, $10 \mathrm{~d}$ and $12 \mathrm{~d}$ in coral concrete are shown in Figure 3. It shows that with the increase of BFRP rebar's bond length in coral concrete, the maximal bond stress is reduced constantly, because BFRP rebar of specimens is buried deeper, thus it is hard to pull out, indicating that the bond force between BFRP rebar and coral concrete is great. However, if bond force between them is distributed to every length averagely, mean bond force will be reduced, because every segment length suffers from incompletely consistent force, resulting in reducing maximal bond stress with it.

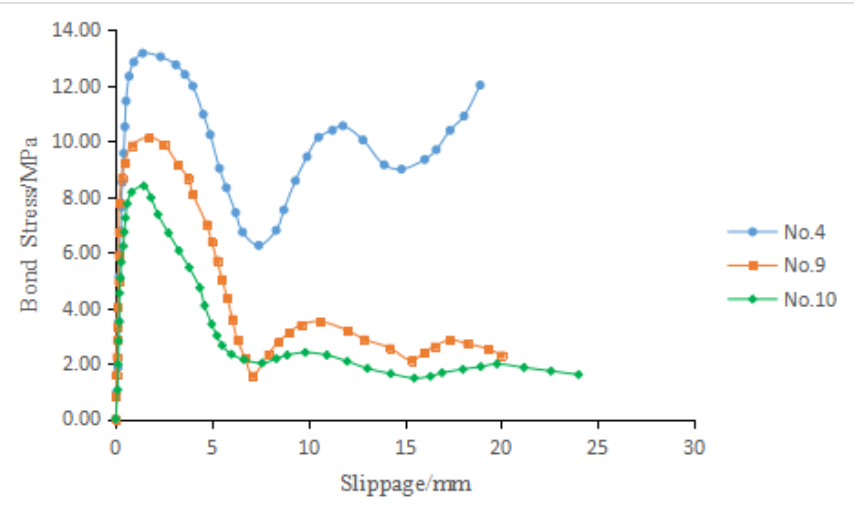

Fig. 3 Bond Stress - Slippage Curves of BFRP Rebar with Different Bond Length and Coral Concrete

\section{Conclusion and Prospect}

(1) Under the same coral concrete compression strength and the same bond length, to increase diameter of BFRP rebar will reduce limit bond strength constantly.

(2) Under the same bond length and the same diameter, to increase coral concrete compression strength will also increase bond strength.

(3) Under the same diameter and the same coral concrete compression strength, there is the inverse proportion relationship between BFRP rebar's bond length and strength

(4) Factors affecting the bond performance between BFRP rebar and coral concrete in the paper are a few. Considering that coral concrete is mainly applied to island and coastal engineering, it is necessary to study influences of high temperature and seawater tide on their bond performance. 


\section{References:}

[1] Han Chao, the Study on Basic Mechanical Property of Coral Concrete Mixing with Seawater [D], Nanning: Guangxi University, 2011;

[2] Wu Fnag, the Experimental Study on BFRP Rebar and Concrete Bond Performance[D], Dalian, Dalian University of Technology;

[3] Xu Chao, Li Zhao and Yang Jibao, the Experimental Study on Mix Proportion of Coral Reef Sand Cement [J], Hydrogeology and Engineering Geology, 2014, 41(5): 70-89;

[4] Zhu Fusheng and Zhang Haixia, Main Factors Affecting FRP Rebar and Concrete Bond Performance [J], Journal of Shenyang Jianzhu University(natural science), 2006, 22(3): 397-401

[5] E. Cosenza, G. Manfredi, R. Realfonzo, Behavior and Modeling of Bond of FRP Re-bars to Concrete[J], Compos. For Cons-tr. ASCE, 1997, 1(2): 40-51 